\title{
Ethical issues across cultures: Managing the differing perspectives of China and the USA
}

Article in Journal of Consumer Marketing · June 1999

DOI: $10.1108 / 07363769910271487$

CITATIONS

53

3 authors, including:

\section{Dennis A. Pitta}

University of Baltimore

88 PUBLICATIONS 1,290 CITATIONS

SEE PROFILE
READS

1,045

Some of the authors of this publication are also working on these related projects:

The Role of Integrated Marketing Communications in Sustainability Marketing, Proceedings of American Society of Business and Behavioral Sciences View project 


\title{
Ethical issues across cultures: managing the differing perspectives of China and the USA
}

\author{
Dennis A. Pitta \\ Professor of Marketing, University of Baltimore, Baltimore, \\ Maryland, USA \\ Hung-Gay Fung \\ Dr Y.S. Tsiang Professor of Chinese Studies, University of Missouri, \\ St Louis, Missouri, USA \\ Steven Isberg \\ Associate Professor of Finance, University of Baltimore, Baltimore, \\ Maryland, USA
}

Keywords China, Consumer behaviour, Ethics, Marketing strategy, National cultures, USA

Abstract US marketers know the US standard of ethics. However, that standard can lead to ethical conflict when Americans encounter the emerging market giant, China. As smaller US companies enter China, the potential for ethical conflict increases. Reducing that potential requires knowledge. Knowing the nature and history of the two cultures can lead to an understanding of the foundation of their ethical systems. Ethics and the expectations within cultures affect all business transactions. It is vital for Western marketers to understand the expectations of their counterparts around the world. Understanding the cultural bases for ethical behavior in both the USA and China can arm a marketer with knowledge needed to succeed in cross-cultural business. Implementing that knowledge with a clear series of managerial guidelines can actualize the value of that understanding.

\section{Introduction}

Western businesspeople often concentrate on the fundamentals. In the business and marketing sense, the fundamentals are:

- $\quad$ sound marketing strategy;

- professional marketing research;

- world-class product development;

- effective pricing;

- motivating promotion; and

- appropriate distribution.

Focusing on the basics makes success in competitive markets possible.

However, serious problems can materialize in business practice between the West and the emerging market giant, China.

\section{Cultural factors}

The difficulty lies in more fundamental issues than product, price, promotion and place. With the transition from domestic-focussed operations to a true worldwide view, other factors are essential for success. One pervasive factor is culture. Culture and the expectations within cultures affect all business transactions. It is vital for Western marketers to understand the expectations of their counterparts around the world. Even at the threshold of the millennium, inability to master the basic cultural factors still leads to failure.

To be accurate, culture is one of the factors that affect business ethics. The Random House College Dictionary defines ethics as, "the rules of conduct 


\section{Differences in systems of laws}

recognized in respect to a particular class of human actions or a particular group, culture, etc.". Different cultures have different rules of conduct and therein lies the issue addressed in this paper. That issue is: understanding the roots of ethics across the two cultures.

Primary cultural values are transmitted to a culture's members by parenting and socialization, education, and religion. There are also secondary factors that affect ethical behavior. They include differences in the systems of laws across nations, accepted human resource management systems, organizational culture, and professional cultures and codes of conduct.

Our objective is not to point out which practices are ethical and which are unethical. Our objective is to understand the differences and outline a means of managing them. What is important is that some cultures might view these practices with different levels of condemnation. Therein lies the problem for managers engaged in cross-cultural transactions. How do they anticipate and manage differences in ethical behavior rooted in differences in culture?

The following discussion concentrates on the differences in the cultures of the USA and China, in an attempt to clarify potential sources of ethical discrepancy.

\section{Ethical behavior in different cultures}

For Americans, the 1980s and 1990s marked the realization of the global economy. Even ordinary consumers know more about the national origin of the products they consume. The biggest impact seems to have been on small businesses. The US Government and many states offer global business help to all businesses. As smaller firms enter the global marketplace, they encounter different ethical frameworks than those of their domestic markets. Smaller firms may be less well-equipped to deal with the differences. This trend has highlighted the need to manage potential ethical conflict before it becomes a problem. Supporting that end, research into the ethics of international management has become a growing field (Jeurissen and van Luijk, 1998; Jackson and Artola, 1997; Honeycutt et al., 1995; Armstrong and Sweeney, 1994).

\section{Cultural conflict}

Newspapers contain stories highlighting the domestic unethical behavior of managers. The behavior includes:

- illegal campaign contributions;

- bribery;

- knowingly selling defective goods;

- hiding information; and

- other troubling acts.

These instances represent individual or organizational misconduct; there is an ethical framework that is not followed. The more serious problem entails two different ethical standards meeting in a business transaction. This situation is characterized as a cultural conflict.

Even in the West, ethical differences can lead to contrasting business practices. The Foreign Corrupt Practices Act, enacted in the USA, is the source of a glaring comparison. US companies, in their worldwide operations, are forbidden to engage in activities that are illegal in the USA. As a case in point, bribery to obtain business is strictly forbidden for a US 
company, no matter where in the world it takes place. Company officers can face jail terms and hefty fines are common.

In some countries, bribery is part of the fabric of life and no business can be transacted without it. Without knowing whom to pay to grease the wheels, companies face frustration and failure. If a US company resorts to bribery, it faces great pressure to hide it, including hiding it in financial statements. In contrast, other countries have a more tolerant or pragmatic view of bribery. As a case in point, at this writing, bribes are explicitly tax deductible in another Western country, Germany.

When considering countries that do not share a common cultural heritage, the challenges can be even greater.

Culture, the basis for business ethics

There is common agreement that a country's culture is directly related to the ethical behavior of its managers. The behavior is exhibited in two main ways: first, by overt actions such as public or corporate statements and actions about ethical behavior; second, by the collection of the group of ethical attitudes and values.

One problem in dealing with culture is that it is difficult to define universally. It represents the values and patterns of thinking, feeling and acting in an identifiable group. While many nations possess the infrastructure of modern, developed civilization, culture represents how people in the civilization interact with one another.

A view that may help understand culture is to look at its levels (Schein, 1985). Schein (1985) proposed that culture has three levels. The most obvious concerns the works of culture, its artifacts. These are apparent and portray some of the values of the culture. Public works, works of art, museums, hospitals and universities can reveal the value that the culture places on the arts and sciences. The Coliseum, in ancient Rome, and its purpose in entertaining the public revealed how Romans valued individual human life.

Rules of conduct

A deeper and less obvious level comprises those things which individuals hold dear and which guide their behavior. They serve as rules of conduct and can be important guidelines for how individuals should or ought to behave. The Japanese elevation of politeness in behavior may reflect the limited physical space in the island nation. However, politeness to others is clearly how the Japanese should behave toward one another. Violations of the norm cause others surprise and anger and sometimes lead to sanctions against the offender.

The third and hidden level represents values, and specifically represents the assumptions we use to perceive and deal with reality. For example, some cultures perceive people as essentially good while others tend to take a more pessimistic view. It is difficult to separate the lower two levels since attitudes and values tend to overlap. However, they form the underpinnings of individual and business interactions.

\section{Dimensions of culture}

The goal of identifying a nation's value assumptions can be achieved by studying the dimensions of its culture. Kluckholn and Strodtbeck (1961) compared a number of cultures across six dimensions, which have been studied by scholars in non-business fields for many years. The six dimensions can be articulated as the following six questions: 


\section{Clear guidelines}

(1) What are society's assumptions about the essential goodness of people? Does the society assume that people are essentially good, bad or both?

(2) What does the society emphasize in interpersonal relations, the individual or the group? Should an individual feel free to act as an individual or should he consider the group before acting?

(3) What is the value of personal space in a society? In some societies, people feel comfortable standing very close to one another. In others, there is an accepted physical distance, a buffer, which should not be entered. In those cultures, people are very uncomfortable standing too close.

(4) What does the society assume about the relationship of man and nature? Is man meant to live in harmony with nature or to dominate it?

(5) What is the role of change in society? Does the culture value stability, and preserving the status quo? In contrast, does the society value progress and change?

(6) Finally, what is society's orientation toward time: past, present or future?

Kluckholn and Strodtbeck (1961) found that each society has a cultural orientation that can be described in terms of these six questions. Knowing the dimensions of culture can help in anticipating potential sources of conflict.

\section{Types of ethical conflict}

Managers like clear guidelines to aid their decision making. A list of rules citing prohibitions and allowed practices is often helpful. Unfortunately, such lists are too simple to guide cross-cultural ethical interaction. For example, gift-giving is not usually prohibited in most cultures. However, in a given culture, giving a gift may be ethical or unethical. In some societies, like China, presentation of a small, carefully chosen business gift conveys a great deal of respect and is a sign that the business relationship is valued by the giver. If there is a problem, it may rest with the receiver who may not trust the giver's motives. In this case, the issue can be understood as one of business etiquette.

Conversely, gifts whose purpose is to influence a decision-maker's judgment is actually or essentially a bribe. They are more universally recognized as such. This leads to a second issue involving basic values. What is the proper place of a bribe in the business context? In Western cultures, bribes are usually not considered "right" or fair and are often against the law. In this case, the conflict deals with fundamental standards of fairness (Kohls and Buller, 1994).

There is a continuum of ethical conflict ranging from simple, rather innocuous practices like giving token gifts to serious issues like employing sweatshop or political prisoner labor. Judging the seriousness of the differences requires a look at the aspects of both the American and Chinese cultures.

The cultural foundation of American ethics

To understand the impact of differences in ethical attitudes toward the conduct of business between the USA and China we should start with the ethical foundations in the USA. There are several key questions to address: 


\section{Puritan origins}

Right to choice
- What constitutes ethics in business?

- What issues and behaviors are important?

- What constitute the ethical standards of business conduct?

Answers to these questions are important to our ability to reconcile differences in the way business agents in each country think and act. Ethical roots in the USA date back to the country's Puritan origins. They tend to be based on a foundation of traditional Judeo-Christian and Western sociotheological laws and principles. Underlying this system is the belief in an intrinsic underlying truth. This belief is central to the biblical system of ethics and morality. Here, moral and ethical bases are provided through the decrees of a sovereign moral authority, God. As a sovereign, God declares right and wrong, providing a general moral and legal framework for organizing a society.

Separately, enlightenment philosophers reached similar conclusions. While Christianity was the predominant religion among the nation's founders, enlightenment philosophy and its focus on "natural law" led to their affirmation of an individual's "inalienable rights". The founders identified three basic "self-evident" truths regarding the "inalienable" rights of mankind to:

(1) life;

(2) liberty; and

(3) the pursuit of happiness;

exercised in an environment in which people are equal under the law.

Equality under the law does not imply equality in the endowment of natural talents, intelligence and abilities. Rather, it means that there exist no a priori claims, against one's life, liberty and/or ability to dispose of one's personal property in the pursuit of his or her personal life goals and activities. Limits on such freedom of choice are imposed only in two important cases. The first is when the individual voluntarily agrees to be bound by such a claim as part of a voluntary contract. The second case involves criminal or civil activity resulting in the harm to another's life, liberty, or property. That activity has led to the imposition of legal penalties as a result of a claim enforced under due process of law. As a result, the USA has become a place where the individual's rights are emphasized, contracts are important, and order in society is a goal.

The importance of an individual's right to choice is the foundation of the belief that competitive markets are the best way in which to organize an economy. The economy's role is to provide the greatest degree of satisfaction to the needs and desires of society. Laws enabling this process to function are designed to deny others the opportunity to deprive an individual of his/her freedoms of choice and property rights via the use of fraud or force. In the absence of fraud and force, any "heads-up" transaction in which property or time is exchanged is perfectly legal if not ethical.

The functioning free market economy has often been described as a "nexus of contracts", whereby individual and corporate economic agents voluntarily agree to exchange money, time, resources and other goods and services in the pursuit of their own economic wellbeing. Since individual and corporate agents are principally responsible for their own wellbeing, they play the role of an advocate whose motivation and behavior is self-interested. As long as 
Satisfy needs of overall society

Nature of business relationship that behavior is absent the use of fraud or force, it is possible to engage in virtually any transaction that does not adversely affect the rights of others. There are both benefits and costs to such a system.

The principal benefits of the market system are that resources are allocated in an "optimal" fashion. The principal cost of this system is that it is designed to best satisfy the needs of overall society, but not necessarily the specific needs of any given individual or group within that society.

Adam Smith, who is given credit for contributing to the design of this system, argued that, while it was important to allow the market economy to function freely, other social mechanisms would need to function in such a way as to make up for its deficiencies. In his book The Theory of Moral Sentiments, Smith outlined the importance of the role played by "institutional society", which is, in essence, charged with the responsibility to teach and encourage the practice of civic virtue in society. Whereby behavior in the market economy is dictated by self-interest, that in the civic society should be driven by the principle of self-control. The three main elements of institutional society:

(1) home;

(2) church; and

(3) school;

are thereby responsible for instilling principles of ethical behavior in society, seeing to it that the practice of such behavior is socially rewarded. Selfcontrolled behavior in civic society may serve to mitigate the adverse effects of self-interested behavior in the commercial markets (Muller, 1993).

The integration of behavioral and ethical codes taught within civic and commercial society serve to make the overall society "decent". In the ideal setting, the civic virtue of self-control will influence commercial transactions in such a way as to maintain a high degree of ethical standards of conduct. While individuals acting out of self-interest in commercial transactions will play the part of advocates, transactions will be negotiated in an environment in which participants will be bound by the truth, and will represent themselves "in good faith". This brings us back to the importance of the traditional ethical foundations of the USA and the way in which transactions are negotiated and completed.

In the USA, business transactions revolve around the contract. The contract, most often a written document, spells out the nature of the business relationship and the obligations of each party to the business transaction(s) covered by the contract. While many transactions are conducted on an informal or non-contractual basis, virtually any significant transaction will be based on a fairly detailed contract to which and by which the parties are bound both legally and ethically. Contracts are negotiated in between parties acting as advocates but in good faith. It is generally accepted that commitments made will be honored to the letter if not the spirit of the agreement. The contract becomes the a priori vehicle for resolving disputes. If the parties to the contract cannot reach agreement, an arbitrator or other third party may be called on to interpret the contract. In either case, however, the contract becomes the principal document governing the relationship.

The importance of the absolute nature of the truth and its role in commercial transactions governed by contracts can be seen in some of the teaching of the Judeo-Christian tradition. Once an agent freely enters into a contract he/she 
agrees to be bound by its points. This is not only a legal but a socially ethical commitment made by the individual to other parties involved in the contract. Ethically speaking, individuals are bound to negotiate in the context of the truth, "saying what they mean" and "meaning what they say".

To summarize the impact of this ethical context on the conduct of commercial transactions, business agents in the USA can be expected to act as personal (or corporate) advocates, attempting to engage in transactions that maximize their own wellbeing. The process of negotiation, however, is intended to be in good faith, where the truth is represented in the words and actions of those participating. Once agreements are reached in this context, the participants are both legally and ethically bound to carry out their obligations and commitments as outlined in the contract. While this type of behavior can, if followed to the letter, be predatory in certain cases, the teaching of the value of self-control in institutional society will moderate the adverse effects of self-interested behavior in the environment where the terms of the transaction are carried out.

\section{Comparison of business culture between China and the USA}

Business culture is built from time-tested and conventional practices. Business practices and ways of thinking over a long period of time lasting hundreds or even thousands of years mold the business culture of a country. China and the USA have different business cultures, in part, because of their differences in history. After the Chinese economic liberalization policies implemented by Deng Xiaoping in 1978, US multinationals have substantially increased their investments in China through joint ventures, setting up subsidiaries and offices. With the increase in partnership business, it is of critical importance that executives in both countries understand each other's business culture. To this end, we will explain and contrast the various aspects of business culture for the two countries in the following section. A caveat is in order in the following generalizations about China, which should be taken with a grain of salt. China is a nation with a diverse and complex culture with contradictory characteristics. For example, the Chinese people are diligent yet they tend to be content with their lot. With respect to religion, they do not believe in one God but they believe in sages. This contrasts significantly with the US view of one God and the importance of organized religion in the country.

It is important to discuss several notions that define Chinese culture and influence business ethics.

\section{Notion of harmony}

The Chinese believe that everything should be in harmony, and they take a long-term view of things. Change can be viewed as disruptive, in particular, if the change is sudden and substantial. As a result, non-action will be better than action. This line of thinking is derived from the teachings of Confucius and Taoism, which, over a long period of time, have a profound impact on the Chinese people.

The notion of harmony is easily understandable for several reasons. First, there are many people in China. Conflict among people who live closely together is inevitable. Without paying proper attention to harmony, the Chinese society would be chaotic. Thus, scholars, philosophers, and rulers have to emphasise the importance of harmony in order to have peace and order in society. Second, dominant religions prevailing in China, such as 
Taoism and Buddhism, stress peace and nature and clearly have an impact on how the Chinese people behave and think.

Americans, however, believe in efficiency and effectiveness. Thus, competition and action that will contribute to the end result are regarded as critical and important. Americans believe in logical reasoning that is based on facts and are usually straight with them. They value the desired end result, which may be disruptive to relations and the normal existing patterns.

\section{Importance of relationship}

The Chinese believe that they are dependent on four social groups, which include relatives, schoolmates, personal friends and the indirect relationship from the three. The Chinese people attach special importance to human feelings. Human relationship is very important to them. In the Chinese language, human relationship is called "guanxi" or connection.

The importance of human relationship is primarily derived from the fact that China has been an agricultural state, where a small and closed community is a normal form of social structure. As a result, the Chinese mentality is to work in groups to accomplish a common goal. As a result, individualism is not singled out to be important in the process. In the Chinese culture, privacy is not so highly valued as in the American culture, whose value judgment is entirely based on individualism. This can be explained in two ways. First, the US Constitution guarantees the rights of an individual, which is the building block of US law. Second, the USA has a relatively short history; and thus old styles and ways of thinking that constrain the spirit of individualism in China do not burden daily life in the USA.

Another reason why the Chinese value human relationship so much is their belief that the "rule of man" is more important than the "rule of law", which can be subject to manipulation and interpretation. This is particularly true because different emperors in different dynasties in the Chinese history designed laws that fit their needs or circumstances.

With this emphasis on man, in China, executives and entrepreneurs work constantly to maintain and expand their networks of guanxi. The connections can extend to other companies and individuals, to Hong Kong, Taiwan and even abroad. Thus, the network of guanxi can be very powerful.

Different cultural backgrounds

Americans gain their identity through their individual achievements and behaviors, although relationship does play a role. The American network of relationship exists and is important for business transactions but appears to be relatively more subtle. Because Americans come from different cultural backgrounds, they are diverse people from various races and cultures. Thus, there are relatively few norms in the USA. It is not unusual to view the USA as the "melting pot" of all cultures. In reality that image is inaccurate. The melting pot never worked completely or immediately. In most cases, English is the glue that holds the nations together. Numerous subcultures co-exist and even second and third generation Americans remember their immigrant heritage. With the freedom and money to travel and relocate anywhere in the country, Americans representing individual immigrant groups can be found all over the nation.

That effect has forced an increased tolerance of diversity. Thus, the USA tolerates all kinds of subcultures. However, at the same time, English as the major language represents the essence of what can be called "Anglo-Saxon American" culture which is the dominant US culture. 
Friendships quickly formed

Chinese self-control
To Americans, business relationships can be separated from personal relationships because business transactions are bounded by legal contracts. Friendships are formed very quickly and can be dissolved as they are formed. In general, Americans are open and easy to make friends with, but the relationship is somewhat superficial, and, for many, it is short-term. Most Chinese view relationships as lifetime commitments, and thus do not make close friends easily unless there is a third well-respected party from both sides who links the two parties together.

\section{Subtlety and explicitness}

The Chinese culture is built on subtlety. For example, the Chinese language is not as precisely structured as the English language. It is based on an abstraction of ideas. Typically, the Chinese people do not usually want to confront each other even if there is disagreement. When the Chinese people are confronted in a situation where they do not like the outcome, they do not usually explicitly indicate how they feel. Outspokenness is not the norm and direct questioning is viewed as rude. The Chinese people do not easily reveal their true feelings to other people. Thus, outsiders have to be insightful in their listening. The expression, "read the tea leaves" can refer to paying attention to words, body language and the speaker's tone of voice.

Courtesy is important in Chinese culture; it is the leading virtue among righteousness, ethics and honor. It is important for the Chinese people to save face for other people, and they are afraid of losing face themselves. Thus, the Chinese do not normally put someone in an uncomfortable position. They do not criticize or ridicule what other people are doing. If someone loses face as a result of other people's action, the situation is serious. Sometimes those who lose face at the hands of another seek revenge. This has important lessons for Western managers. Agreements with a Chinese manager must not lead to loss of face and extraordinary efforts to preserve face may be necessary.

The Chinese people do not like saying "no" directly. Instead, they may say, "I will see what I can do". If they say something like "it is not convenient", this basically means either "no" or "it will take time and permission to do".

The Chinese typically give hints to others about what they really want. This contrasts with the frankness in American culture. The Chinese get used to hinting because they try to learn self-control; its importance has been rooted in ancient times. Self-control tends to make people appear shy in revealing their ideas and thoughts in public places. To illustrate the importance of subtlety, here is an example. If a Chinese person wants to borrow a book or money from a friend, the person would not ask for the book or money directly. Instead, he/she will give hints about the book or his/her need for the financial matters. A sincere friend will directly offer the book or money; otherwise, the hint will be ignored.

In many cases, the Chinese people speak openly and directly, especially if an important principle or a critical matter is at stake. In addition, if they are dealing with close friends or if the situation is not hurting people, they will be willing to speak more openly.

\section{Communication style}

The Chinese people value silence, which is considered to be important in daily activities; silence is reserved for reflection and careful thinking. The Chinese people are strong believers of the English proverb: Speech is silver but silence is golden. 


\section{Larger-than-life folk heroes}

\section{Chinese people are pragmatic}

It is important for Chinese individuals to have their speech consistent all the time. Thus, the Chinese do not usually talk too much because they believe that the more they talk, the more mistakes they will make. Americans like to talk and tend to be uncomfortable when there is a gap of silence in the conversation. Some Americans view the silence as a tough negotiating technique. It seems like a stone wall that frustrates communication. In fact, it is a cultural value that is different from the corresponding American cultural value.

Another difference centers on the use of exaggeration. Steeped in a tradition of the "tall-tale" of the frontier, Americans know about larger-than-life folk heroes like Paul Bunyan and Casey Jones. Thus, some Americans believe it is all right to exaggerate. Fluency and the "gift of the gab" are generally viewed as admirable and desirable. American political figures often gain office on the strength of their eloquence. This sharply contrasts with the derogatory notion of eloquence in Chinese customs. This is a bit surprising since the Chinese language is colorful and expressive.

The fact that the Chinese prefer not to talk too much has implications for the advertising business, which is growing more important in China. After Deng Xiaoping began to implement economic reforms in China, corporations have utilized many marketing tools such as advertisements to sell their products. This difference in cultural preferences is the source of potential conflict. Explicitly, exaggeration, called trade puffery, is allowed in US advertising. In fact, consumers and regulators alike expect it.

The essence of advertising is to promote a product and it is useful to create fantasy in showing the needs the product satisfies. However, this may not fit comfortably with the Chinese culture if it is not done properly. Chinese people in general value inner beauty or substance more than the look or style. Therefore they would frown on the advertisements that contain extravagant accounts of products and services. Some still think advertisements are ways to cheat people. Thus, it is important to select appropriate words in promoting the products on TV and other media in China. That is, the focus of advertisements should be on delivery of product education and knowledge. Coupled with the desire not to create loss of face, comparative advertisements may create problems for the advertiser and should be avoided.

Another difference between the two cultures is in the way the two peoples think. Thinking is quite different from talking. In terms of the thinking process, the Chinese people are pragmatic and take actions that fit the existing patterns. Thus, they prefer the actions that are not too disruptive. In general, the Chinese do not think linearly, i.e. from one point to another in a straight line. In many ways, Americans, like the Chinese, are pragmatic. Americans differ because they think in a linear fashion proceeding from point $\mathrm{A}$ to $\mathrm{B}$ to a final conclusion at $\mathrm{C}$. Americans look toward a solution, which may be innovative, disruptive or revolutionary. Americans believe that most productive thinking is linear and rational. In problem solving, the results or outcome should be based on concrete facts. For Americans, problem solving-thinking behavior is different from the trade puffery of advertising.

Most cultures have an ingrained sense of physical space and how people should interact. Western culture has developed several traditions that have implications in business. The handshake is a common, expected ritual when meeting someone. The right hand is chosen as the hand to shake. The ritual 


\section{Do not like touching}

\section{Americans open and straightforward}

and the choice of hand stem from interactions during the days of knights and swords. Most people are right-handed, so are most warriors. Shaking the right hand shows that there is no hidden weapon, ready to be used. Thus handshaking was originally an expression of trust. In essence, the handshake says, "I meet you weaponless, trusting you".

In terms of physical contact, the Chinese people do not like touching. This contrasts with the meaning of touching in Western culture. Between same sex individuals, a touch on a shoulder, hand or arm may be a statement of polite affection between friends. Some Americans touch business acquaintances politely to express the sentiment, "We are friends".

In contrast, Chinese do not like to be touched physically. In addition, they avoid direct eye contact with another person out of respect of the other's private space. When two strangers meet, they have to maintain a physical distance to avoid touching.

This differs markedly in the USA. Direct eye contact is very important for showing sincerity in the American society. This may also have its origins in the day of knights and armor. Looking someone directly in the eye implies that you are not looking for a vulnerable area to use a weapon. Thus, you send a message, "I mean no harm".

Americans like to stand at about an arm's length away from each other, defining their comfort zone. This also conveys a sense of trust because the two individuals stand in a mutually vulnerable space. In certain areas, like Japan, the physical space is about three to four feet, the space needed for two people to face each other and bow politely. In the Middle East, physical space may be as little as a foot - conveying a heightened sense of trust. An American meeting with a Saudi colleague may feel very uncomfortable with the limited separation space and even back away to increase it. This is analogous with the discomfort a Chinese manager might feel toward an American's comfort zone.

When the Chinese say "yes", it basically means that they are listening to what you are talking about. It does not necessarily mean that they agree with you. However, Americans are open and straightforward to deal with.

Therefore, when they say "yes", it really means positive and affirmative.

American people usually greet others (relatives, friends and strangers) by saying "Hi!" In the Chinese culture, strangers will consider this greeting as shockingly inappropriate. In this case, you are supposed to be quiet when you meet a stranger. In contrast, friends and relatives expect, "How are you?" Using "Hi" as a greeting to them will be considered to be "cold".

\section{Negotiation}

Business typically involves negotiation and bargaining. Different cultures have different models of thinking and ways to solve problems. Negotiation with Chinese people clearly is different from negotiation in the Western countries.

In China, negotiations and contracts should link the association between people by confirming the strong human bond instead of resorting to legal binding. Traditional Chinese culture advocates that benevolence should be the guiding principle of association among people. This principle, admittedly limited, does influence many Chinese people.

Many Americans view negotiation and the signing of a contract as the final stage of association for a business. However, for Chinese managers, it is the 


\section{Banquets mechanism for} learning first step to a deeper relationship. Continued negotiation is common because a legal contract does not necessarily give one the upper hand. This way of doing business is closely related to the "rule of man" principle discussed earlier.

Many Westerners believe that the Chinese businesspeople use banquets as a means to get a better bargaining position. Banquets are a mechanism for learning a bit more about the other side before the start of formal negotiations. Moreover, expect the Chinese to conduct business while all are eating and drinking at the banquet table.

Americans in negotiations usually openly discuss advantages, disadvantages, and alternatives. The Chinese would discuss and bargain as well, but the key in the negotiation process is to establish common feelings or bonds between the parties. The strategy is to achieve a win-win goal situation. That is, both sides can win. This contrasts with the one-sided negotiations where the winner takes all. Many Chinese people would consider the win-loss strategy immoral. However, the Chinese may use the feelings of friendship that they have built to their advantage to get some concessions in the negotiation process.

Because the Chinese people in general do not like to speak too much, it is important in the negotiation process to present objective facts without subjective feelings. There is a common saying in China - facts speak louder than eloquence. This principle of presenting indisputable facts is important on the negotiation table.

The Chinese prefer contracts that do not have too many details and prefer all issues to be subject to further negotiation afterwards, even after the signing of the contracts. However, they are meticulous note-takers and will exploit verbal comments made during negotiation that are not part of the written contract. In contrast, Americans are very legalistic and like to spell out all the details in the contracts, which will be backed fully by the US legal system.

\section{Rule of banquet}

As mentioned above, the Chinese pay much attention to eating and drinking. Generally speaking, Western food is not as meticulously prepared as Chinese food. The Chinese people have a lot of excuses for eating. In a business trip to China, the banquet is inevitable. American managers should learn the characteristics of banquets diligently, before visiting China. Both banquet customs and the cuisine will be unfamiliar. China, like the USA, has regional differences in cuisine. All the different versions will each be different from American "Chinese food". Moreover, hosts tend to order expensive delicacies that are even more exotic. The result is that most of the food will be a surprise. The prepared manager will learn what to expect so that he/she can be a gracious guest.

Banquets are usually held in restaurants, in private rooms that have been reserved for that purpose. All members of the business delegation should arrive together and on time. As a guest, you have to wait until your Chinese hosts invite you to sit at a seat according to their arrangement. It is not polite to select your own seat because the prearranged seating chart is based on rank and seniority. Usually, the banquet table is round to accommodate eight to ten people sitting together.

At the banquet table, one can use chopsticks or forks to reach the main course. If you cannot reach the courses on the opposite side of the table, it is 


\section{Concerned with numbers}

unwise to stand up and stretch your arm across to reach the food. In the American style, it is quite natural to ask someone to pass the food. In China, it is not desirable, and this is considered to be impolite. Instead, you can talk to the Chinese friends beside you and give hints. The Chinese people are very sensitive to the hints.

After your Chinese associates invite you for a banquet, it is proper to return the favor unless time or other constraints make it impossible. If possible, a third party should relay your invitations to the Chinese. If for some reason the Chinese must refuse the invitation, they will feel more comfortable telling the third party than speaking directly to you.

Although many people consider that the use of banquets in China is uniquely designed as such for better negotiation and networking, it should be noted that Chinese do observe the American style of network by using club members to achieve similar purposes. The difference between the Chinese and the American networking is only in style.

\section{Taboos}

China has many taboos, which, if violated, may hurt one's friendship or business. These taboos are primarily based on religious beliefs, superstition and certain social norms.

The Chinese people are concerned with numbers, which may signal fortune to them. As a result, using a lucky number such as 1688 for a business phone number or house number is important for the Chinese people. The reason for using 1688 is because it means "all the way to riches" when pronounced in Cantonese.

In addition, the Chinese people are superstitious about their business success. If someone accidentally says something bad about their business, the bad signs will trigger future bad luck, which in turn may be believed to cause the downfall of the business. There is a well-known saying in China that for one's success, it depends on the following factors in the order of importance:

(1) fate;

(2) luck;

(3) feng-shui [1];

(4) accumulation of good deeds[2]; and

(5) knowledge.

The list clearly reflects the importance of uncontrollable factors, which are believed to be critical in contributing to one's success. Thus, it is not difficult to see that the Chinese people have many taboos.

Americans, by and large, believe that hard work will pay off and one can achieve anything one desires. Because of the scientific mentality, Americans are relatively less superstitious than the Chinese people, especially in the running of business. To be successful, Americans should be knowledgeable about and sensitive to Chinese beliefs.

\section{Strategies for resolving ethical conflict}

We have shown some of the relevant differences between American and Chinese managers. They have the potential for several types of conflict and misunderstanding. Kohls and Buller (1994) list seven pragmatic approaches to resolving ethical differences. The authors note that the approaches are not 


\section{Unethical conduct}

\section{Education and persuasion}

meant to be exhaustive or mutually exclusive. They do provide a useful range of possible options that managers might employ to avoid problems.

One response to cross-cultural ethical differences is avoiding. Avoiding has use in many general business content areas, not just the realm of ethics. For example, avoidance is often used in families and business relationships. In this case, the partners may choose to ignore the problem in the hope that it will go away. Too often the problem continues until it surfaces in an outburst. Avoidance is a potentially useful strategy for the stronger of two parties. It is especially useful when the costs of confrontation are high. The boss, for example, may prefer the status quo. In numerous examples, he may ignore complaints or requests for improvement of pay, working conditions, benefits or other costly changes. Power may allow him to maintain the status quo.

In a cross-cultural business relationship, avoiding is sometimes used when one party is stronger than the other. A supplier or agent may engage in unethical conduct, but confronting the activity may result in loss of sales or market share. Thus, the costs of confrontation may be too high. Avoiding results in a kind of "do not ask, do not tell" posture.

Another resolution strategy is forcing. Forcing simply means that one party forces its will on the other. As with avoiding, power is necessary for this strategy. The stronger party can demand its way. For example, importers with controlled access to domestic markets can demand concessions or specific behavior of their suppliers. Markets in some economies are or have been essentially closed to outside firms. In the past it has been close to impossible for a US company to set up a business operation in Japan, without a strong domestic partner. This situation manifests itself in the large number of joint ventures in Japan. In such a relationship, the Japanese partner can demand that things be done in a particular way that might conflict with US practices.

A third possibility is to use a combination of education and persuasion. US companies with operations in foreign countries have the opportunity of communicating the benefits of employee safety and human resources management policy. This strategy has the advantage of benefiting from communication.

Fourth on the list is infiltration. This refers to the spread of an idea or principle in a society. Marketing ideas, such as a consumer orientation or an emphasis on product quality, serve as examples of ideas that were introduced from the USA into several other cultures.

A strategy somewhat related to education and persuasion is negotiation and compromise. It is based on communication and leads to some kind of settlement. However, in this case, both parties may have to give up something - the compromise. This procedure may result in one or both parties feeling dissatisfied with the resulting outcome. The implication may be that nothing has really been resolved.

Another strategy, accommodation, results when one party adapts to the ethic of the other. A foreign company may agree to the ethical view of a US partner because, otherwise, no business may be possible.

The last strategy, collaboration and problem solving may result in the best outcome. Under a collaboration and problem-solving strategy, both parties may work together to reach a mutually beneficial and acceptable solution. Of all the listed strategies, this one offers the highest probability of actually 
Negotiation and compromise bridging the difference separating the parties. The example of the USA and the People's Republic of China (PRC) agreeing on the Shanghai accords follows this strategy. The accords contained numerous articles. In this example, the USA agreed not to recognize "two Chinas - the PRC and Taiwan". Instead, the USA agreed only to maintain diplomatic relations with the PRC government. This feature represented a deep-seated desire on the part of the PRC government to be recognized as the sole government of the Chinese nation. Conversely, the agreement that the USA could supply the defense needs of Taiwan, if it did not escalate the quantity and quality of arms, represents a need on the part of the USA not to abandon a long-time ally completely.

On the surface, the collaboration and problem-solving strategy looks a lot like a negotiation and compromise solution. However, the focus is more on uncovering problems in the ethical relationship and solving those problems to mutual satisfaction.

The seven strategies form a series of strategic alternatives that can be selected to deal with a particular ethical conflict. Kohls and Buller (1994) are clear that no single conflict reduction strategy is really better than another. Each may be appropriate in a specific situation.

That said, the collaboration and problem-solving strategy has another advantage in USA-China managerial co-operation. It lays the foundation for establishing a relationship of trust that is a part of the guanxi concept.

\section{Summary}

Culture forms the foundation for ethical behavior and determines what is ethical and what is considered unethical. We have shown some of the crucial differences between the business and ethical cultures of the USA and China. The differences include a context versus content orientation. In China, guanxi, the set of connections or relationships, form the context of business. Within that context exist a series of expectations and a level of trust. When Chinese managers negotiate a contract, they rely not on the content of the contract but the context in which it was negotiated. What is important is the relationship among the individuals. If a sticky detail comes up, Chinese managers feel that communication and relationships will solve it. There is less concern about meeting contract conditions, since the contract is viewed as a symbol of the relationship among partners.

In contrast, Western managers view the content of a contract as most important. The specific wording, the dates, the amounts, the responsibilities are spelled out clearly. To an American manager, negotiating the details implicitly means striving to meet the demands of the contract. Failure to do so would embarrass an American, a loss of face. The situation is even more pronounced when German managers are involved. German culture is even more high content than US culture. Every point, value, date and article in a German contract would be gospel.

Other potential ethical conflicts arise simply from the different values inherent across cultures.

\section{Managerial implications}

Several important implications can be drawn from the paper. Perhaps the most important one revolves around the importance of respecting the terms of a contract. Americans will do so and also expect others to. Chinese managers do not regard a contract with the same degree of importance. 

who did not understand that deadlines would not be met, even though they were spelled out clearly. In addition, some Chinese managers are irate to learn that their American partners had no intention of modifying an agreement after signing. Worse, the common business practice of adding a penalty or fee for the modifications seems like thievery.

Chinese and American societies place different emphasis on interpersonal relations, the individual and the group. In the USA, the rights of individuals are safeguarded and individual uniqueness and diversity are valued. In China, the individual is less important. In human resources decisions, Chinese managers may attach less importance to individual rights.

Conversely, Chinese managers may attach great importance to their network of connections. Outsiders may have difficulty in penetrating the network. Even lower cost, higher quality, higher profit proposals, essentially "better" offers, from outsiders may not be accepted in China. This may lead to the impression of unethical favoritism. In fact, it is just an honored system of working.

We considered the question of society's assumptions about the relationship of man and nature. Chinese managers live in harmony with nature.

Americans feel that man should dominate it. This difference in orientation may lead Americans to be perceived as unethical polluters and destroyers of old artifacts. It is important to understand the Chinese position and insure that it is respected. Otherwise, business dealings may be difficult.

A potential clash of cultures revolves around the role of change in society. The Chinese culture values stability, and preserving the status quo. Changes, if necessary, should be evolutionary. In business dealings, change, especially an increase in prosperity, is valued. However, too rapid change upsets balance. In contrast, US culture values progress and change even at the expense of traditional values. The implication is that US managers must respect the values of their Chinese counterparts. This will require Americans to have great patience.

Other problems may be rooted in society's orientation toward time. Chinese revere the past and pray to elders and deceased relatives for help. The concept of time has a longer duration for most Chinese. In contrast, most Americans have little concern for the past and live in a youth culture. They live in the present and plan for the future. Americans also have a shorter conception of time; things must happen quickly since "time is money". American managers cannot underestimate the accommodations necessary to deal with this difference.

In short, knowing the differences in culture between the two societies can help avoid costly problems and failure. Employing an expert in the other side's culture and business practice can be the best insurance of success.

\section{Notes}

1. Feng-shui (wind-water) is the existence of harmony that combines the environment setting for successful and happy outcomes. For example, when Donald Trump opened up his business office in New York City several years ago, he hired several experts in the application of feng-shui principles to design his office and made necessary changes for the office's design and furniture arrangement.

2. The belief that previously performed good deeds affect future events is rooted in Buddhism, which believes the cause-effect relationship. 


\section{References}

Armstrong, R.W. and Sweeney, J. (1994), "Industry type, culture, mode of entry and perceptions of international marketing ethics problems: a cross-cultural comparison", Journal of Business Ethics, Vol. 13, pp. 775-85.

Honeycutt, E., Siguaw, J. and Hunt, T.(1995), "Business ethics and job-related constructs: a cross-cultural comparison of automotive salespeople", Journal of Business Ethics, Vol. 14, pp. 235-48.

Jackson, T. and Artola, M., (1997), "Ethical beliefs and management behaviour: a crosscultural comparison", Journal of Business Ethics, Vol. 16, pp. 1163-73.

Jeurissen, R.J.M. and van Luijk, H.J.L. (1998), "The ethical reputations of managers in nine EU-countries: a cross-referential survey”, Journal of Business Ethics, Vol. 17, pp. 995-1005.

Kluckhohn, F.R. and Strodtbeck, F. (1961), Variations in Value Orientations, Row Peterson, Evanston, IL.

Kohls, J. and Buller, P. (1994), "Resolving cross-cultural ethical conflict: exploring alternative strategies", Journal of Business Ethics, Vol. 13, pp. 31-8.

Muller, J.Z. (1993), Adam Smith in His Time and Ours: Designing the Decent Society, Free Press, New York, NY. 